\title{
ХАРАКТЕРИСТИКА УЧЕБНОЙ ПРОГРАММЫ ПО СПЕЦИАЛЬНОСТИ МУЗЫКАЛЬНОГО ОБРАЗОВАНИЯ В РОССИИ: НА МАТЕРИАЛАХ ПЕДАГОГИЧЕСКОЙ ПРАКТИКИ РПГУ
}

Bao Nuan

Summary: The article analyzes the curriculum in the specialty of music education on the example of materials of pedagogical practice of The Herzen State Pedagogical University of Russia. The present study is based on the curriculum of bachelors training in the direction of «music education», its characteristics, the purpose of training, a brief description of the main subjects, the curriculum, and justified the inclusion of disciplines in this curriculum. According to the results of the study, it was found that the program for teacher training in the field of music set certain requirements for future teachers, the curriculum is drawn up in such a way that the entire program is effectively implemented in the learning process, and the disciplines enshrined in the program reflect the latest trends in the field of music education.

Keywords: pedagogy, The Herzen State Pedagogical University of Russia, music, curriculum, curriculum, music education.

\section{CHARACTERISTICS OF THE CURRICULUM IN THE SPECIALTY OF MUSIC EDUCATION IN RUSSIA: ON THE MATERIALS OF THE PEDAGOGICAL PRACTICE OF RSGU}

\author{
Бао Нуань \\ Аспирант, Российский государственный педагогический \\ университет имени А.И. Гериена \\ baonuan@foxmail.com
}

Аннотация: В настоящей статье проводится анализ учебной программы по специальности музыкального образования на примере материалов педагогической практики РПГУ им. А.И. Герцена. За основу настоящего исследования взята учебная программа подготовки бакалавров по направлению «музыкальное образование», приведена ее характеристика, цель подготовки, краткая характеристика основных предметов, учебного календарного плана, а также обосновано включение дисциплин в данную учебную программу. По результатам исследования было установлено, что в программе по подготовке педагога в области музыки установлены определенные требования к будущим педагогам, учебный план составлен таким образом, что вся программа эффективно реализуется в процессе обучения, а дисциплины, закрепленные в программе, отражают последние тенденции в области музыкального педагогического образования.

Ключевые слова: педагогика, РПГУ им. А.И. Герцена, музыка, учебная программа, учебный план, музыкальное образование.

В настоящей работе будет исследоваться учебная программа по специальности «Музыкальное образование. Очная форма обучения» РПГУ.

цесса обучения. Однако для того, чтобы провести характеристику учебной программы по специальности музыкального образования в России, необходимо разобраться, что такое учебная программа.

Учебная программа в энциклопедическом словаре определяется как «содержание и план деятельности, работ» [1], в Федеральном Законе №273-Ф3 «Об образовании в Российской Федерации» образовательная программа определяется совокупность характеристик образования, которая включает в себя объем образовательной программы, его содержание и планируемые результаты, организационно-педагогические условия, которые необходимо создавать в процессе обучения, а также формы аттестации, календарный учебный график, рабочие программы учебных предметов, курсов и оценочных и методических материалов [8]

Целью настоящего исследования является характеристика учебной программы по специальности музыкального образования Российского государственного педагогического университета имени А.И. Герцена (РПГУ)
Целью исследуемой учебной программы является профессиональная подготовка педагогов с музыкальным образованием, обладающих знаниями в области музыки и педагогики, владеющими современными методами преподавания и мотивированных на выполнение эстетических, просветительских и образовательных задач в области музыкального искусства. Следует отметить, что в РПГУ им. А.И. Герцена обучение по исследуемой программе проходит на русском языке.

Среди преимуществ настоящей программы следует выделить то, что будущие музыканты-педагоги могут раскрыть свои таланты как в области музыки, так и в области педагогики участвуя в большом количестве мероприятий, которые проходят как в стенах университета, так и за его стенами. Среди таких мероприятий можно выделить лекции, конференции и практические семинары с участием известных профессоров российских и зарубежных консерваторий и университетов, творче- 
ские встречи с выпускниками прошлых лет, а также фестивали и конкурсы, которые проходят как в России, так и за рубежом. Стоит также отметить, что РПГУ им. А.И. Герцена является основоположником таких конкурсов, как «Санкт-Петербург в зеркале мировой музыкальной культуры», «Педагог-музыкант в контексте современной культуры» и международный конкурс вокалистов им. Штокова.

Заслуживает внимания тот факт, что в РПГУ им. А.И. Герцена дружное студенческое сообщество, работает Студенческая филармония, хоровые коллективы, такие как «Евразия», джазовые ансамбли и другие музыкальные коллективы, в которых будущие педагоги смогут развить свои музыкальные и педагогические навыки.

Стоит отметить, что выбранная программа рассчитана на 4 года и соответствует уровню образования «Бакалавриат», направление 44.03.01 «Педагогическое образование». Среди требований к начальной подготовке абитуриентов выделяются следующие:

1. Документ государственного образца (о среднем (полном) общем образовании (аттестат);

2. Документ о начальном профессиональном образовании (диплом);

3. Документ о среднем профессиональном образовании (диплом), о высшем профессиональном образовании (диплом);

4. Сдача вступительных экзаменов, которые определяются Правилами приема в РПГУ им. А.И. Герцена.

Вступительный экзамен разделен на две части:

1. Исполнительское мастерство (инструментальное исполнительство, вокальное исполнительство);

2. Сольфеджио (интонирование, слуховой анализ)

Следующая составляющая учебной программы - это календарный учебный план, который представляет собой часть учебной программы, являющейся характеристикой образования и определяет количество учебных дней, недель, продолжительность каникул, производственной практики, экзаменационной сессии, научноисследовательской работы, подготовки к летней школе.

Учебный план по специальности «музыкальное образование» представлен на рисунке 1.

Содержание учебной программы представляет собой совокупность предметов и модулей, которые студенту необходимо освоить [2]. В РПГУ им. Герцена содержание учебной программы по специальности музыкального образования представлена следующим списком предметов и модулей:

1. История;

2. Философия;

3. Иностранный язык;
4. Культура речи;

5. Экономика образования;

6. История художественной культуры;

7. Музыкальная эстетика;

8. Эстетика джазового искусства;

9. Современная массовая культура;

10. Социология музыки;

11. Информационные технологии;

12. Основы математической обработки информации;

13. Естественнонаучная картина мира;

14. Музыкальная информатика;

15. Психология;

16. Безопасность жизнедеятельности;

17. Педагогика;

18. Методика обучения и воспитания (музыкальное образование);

19. История зарубежного музыкального искусства;

20. История отечественного музыкального искусства;

21. Сольфеджио и структура музыкального языка;

22. Гармония;

23. Полифония;

24. Анализ музыкальных произведений;

25. Дирижерско-хоровые дисциплины;

26. Музыкальный фольклор;

27. Музыкально-инструментальное исполнительство;

28. Вокальный класс;

29. История и теория музыкального образования;

30. Музыкальная психология и психология музыкального образования;

31. Основы творческого музицирования;

32. Модуль «Музыкально-театральное искусство»;

33. Модуль «Музыкальное искусство»;

34. Модуль «Музыкальный фольклор»;

35. Модуль «Музыкально-компьютерные технологии»;

36. Модуль «Менеджмент в музыкальном образовании»;

37. Модуль «Дошкольное музыкальное образование»;

38. Модуль «Вокальное искусство»;

39. Подготовка к летней практике;

40. Физическая культура и спорт.

Для наиболее полного отражения характеристики учебного плана были проанализированы некоторые предметы изучаемой программы. Так, содержание курса «История художественной культуры» строится на понимании художественной культуры в качестве пространства, в котором взаимосвязаны все виды художественной деятельности (изобразительные, театральные, музыкальные и т.д.). Освоение курса «История художественной культуры предполагает изучение таких аспектов, как морфологический, институциональный и духовно-содержательный.

Морфологический аспект предполагает изучение иерархии видов искусств, их взаимосвязи, а также историю развития видов и жанров искусства. Институциональный аспект предполагает изучение созидания, хранения, 
распространения, восприятия и оценки художественных произведений. Духовно-содержательный аспект предполагает изучение ключевых идей художественных произведений конкретной исторической эпохи.

Соответственно, можно сделать вывод, что главной задачей курса является раскрытие сущности исторического развития мировой культуры, выявление смыслов культурных идей, воплощенных в конкретных исторических эпохах и художественных картинах мира. Целью курса является формирование у студентов навыков и способностей к самостоятельному изучению и освоению художественных ценностей и применению полученных навыков в профессиональной педагогической деятельности.

В настоящее время происходит быстрое развитие информационных технологий, поэтому задачей каждого образовательного учреждения является оснащение учреждения средствами, которые позволят использовать в процессе обучения информационные технологии, тем самым существенно упрощая процесс обучения. РПГУ им. Герцена не является исключение, поэтому в учебную программу по специальности музыкального образования включен такой предмет, как «Музыкальная информатика». В содержании данной дисциплины раскрываются вопросы компьютерной музыки. Рассматриваются специальные методологические подходы к ведению педагогической работы, современного искусствоведения и методологией научно-исследовательской деятельности в области музыкального образования с помощью использования последних достижений информационных технологий [4].

Как известно, РПГУ им. Герцена является педагогическим университетом, поэтому очевидно, что в учебной программе по специальности музыкального образования присутствует такой предмет, как педагогика. Настоящий курс является обязательным для студентов направления «Педагогическое образование» и включает в себя следующие дисциплины:

1. История образования и педагогической мысли;

2. Педагогика школы;

3. Решение профессиональных задач.

Данные дисциплины тесно взаимосвязаны как по содержанию, так и по форме проведения практических занятий, а также по организации самостоятельной работы студентов. Стоит заметить, что основной упор при изучении данных дисциплин идет на развитие навыков использования знаний о педагогическом процессе, взаимодействия с учениками, их родителями и коллегами по работе в процессе решения профессиональных педагогических задач [5].

Смежным предметом с педагогикой является методи- ка обучения и воспитания (музыкальное образование). Данный предмет был включен в учебную программу в связи с ее музыкальным уклоном. В содержании данной дисциплины исследуется становление профессиональной компетентности бакалавра посредством обогащения имеющегося педагогического опыта историко-педагогическим знанием, методами историко-педагогического познания.

Особую роль при изучении данной дисциплины занимает решение таких профессиональных задач, как:

1. Формирование интереса к истории педагогики как основы профессионального роста;

2. Формирование знаний истории педагогики различных стран и народов;

3. Формирование навыков анализа первоисточников в области профессиональной педагогики;

4. Развитие педагогической эрудиции;

5. Развитие навыков организации образовательного процесса с использованием информационных технологий.

«Музыкальная психология и психология музыкального образования» является важным предметом в учебной программе по специальности музыкального образования, так как будущий преподаватель должен понимать каждого студента в связи с антропологической тенденцией в музыкальном образовании, которая заключается в том, что каждый студент рассматривается как личность, учитываются его личные качества, умения и навыки. Поэтому в данной дисциплине формируется способность реализовывать учебные программы базовых и элективных курсов в различных образовательных учреждения; готовность применять современные методики и технологии, в том числе и информационные, для обеспечения качества учебно-воспитательного процесса на конкретной образовательной ступени конкретного образовательного учреждения. В содержании дисциплины исследуются базовые положения в области музыкальной педагогике; специфика музыкальной психологии и ее основные категории; принципы взаимосвязи музыкальной педагогики и психологии [6].

Самым важным предметом в музыкальном педагогическом образовании является «История и теория» музыкального образования» ввиду того, что при освоении данной дисциплины изучаются основные этапы развития художественно-педагогической теории и практики с точки зрения культуры и искусства. Также изучаются основные концепции художественного образования и воспитания в контексте структуры образовательного процесса. При изучении данной дисциплины уделяется внимание также развитию мирового педагогического процесса с последующим его сравнением с педагогическими процессами различных стран. Особенности современного развития образовательного процесса в 


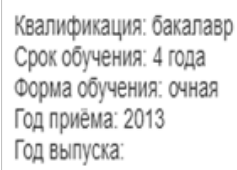

График учебного процесса

\begin{tabular}{|c|c|c|c|c|c|c|c|c|c|c|c|c|c|c|c|c|c|c|c|c|c|c|c|}
\hline weç & сентторо & 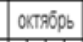 & Hоя 0 p & дeráóp & & 9нварь & февраль & март & апрель & май & & 10Hb & & июль & & aвууст & Teop. & & & & & Hepá6 & \\
\hline Heдела & \begin{tabular}{l|l|l|l|l|l|} 
& 2 & 3 & 4 & 5
\end{tabular} & 5678 & \begin{tabular}{|l|l|l|l|l|l|l|l|l|}
10 & 11 & 12 \\
\end{tabular} & \begin{tabular}{|l|l|l|l|l|}
13 & 14 & 15 & 16 & 17 \\
\end{tabular} & & 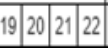 & \begin{tabular}{|l|l|l|l|}
23 & 24 & 25 & 26 \\
\end{tabular} & \begin{tabular}{|l|l|l|l|l|l|l|l|l|l|}
5 & 28 & 29 & 30 & 3 \\
\end{tabular} & \begin{tabular}{l|l|l|l|l}
31 & 32 & 33 & 34 & 35
\end{tabular} & \begin{tabular}{l|l|l|l|l|l|l|l|l|l|}
5 & 36 & 37 & 38 & 39
\end{tabular} & \begin{tabular}{l|l|l|l}
39 & 40 & 41 & 42 \\
\end{tabular} & \begin{tabular}{|l|l|l|}
42 & 43 & 44 \\
\end{tabular} & \begin{tabular}{l|l|l|l|}
44 & 45 & 4
\end{tabular} & \begin{tabular}{|l|l|l|}
46 & 47 & 48 \\
\end{tabular} & 8495 & \begin{tabular}{l|l|l}
50 & 51 & 52
\end{tabular} & 52 чесу. & & & & & वнय & a. Bcero \\
\hline 1 1 yppc & & & & & & \begin{tabular}{ll|l|l|} 
& 3 \\
\end{tabular} & & & & & & \begin{tabular}{|l|l|}
3 & $y$ \\
\end{tabular} & $\begin{array}{lll}y & y \\
\end{array}$ & \begin{tabular}{l|l|l|}
$y$ & $K$ & \\
\end{tabular} & $K$ & \begin{tabular}{|l|l|l}
$K$ & $K$ & $K$ \\
\end{tabular} & 37 & & -1 & & $\pi$ & & 52 \\
\hline $2 \mathrm{kppc}$ & & & & & 5 & \begin{tabular}{l|l|l|l|l} 
& 3 & 3 & $K$ \\
\end{tabular} & & & & n & & \begin{tabular}{|l|l|}
$3 \Pi \Pi$ \\
\end{tabular} & $\begin{array}{ll}\pi \\
101\end{array}$ & \begin{tabular}{l|l|l}
$\Pi$ & $K$ & $K$ \\
\end{tabular} & $k$ & \begin{tabular}{l|l|l}
$\mathrm{K}$ & $\mathrm{K}$ & $\mathrm{K}$ \\
\end{tabular} & 36 & $6-$ & $5-$ &  & Et & & 52 \\
\hline $3 \mathrm{mypc}$ & & & & & & \begin{tabular}{ll|l|} 
& 3 & $K$ \\
\end{tabular} & & & & & & \begin{tabular}{l|l} 
& 3 \\
\end{tabular} & \begin{tabular}{l|l|}
3 & $K$ \\
\end{tabular} & \begin{tabular}{l|l|l|}
$K$ & $K$ & $K$ \\
\end{tabular} & $\mathrm{~K}$ & \begin{tabular}{l|l|l}
$K$ & $K$ & $K$ \\
\end{tabular} & 36 &  & -1 & & - & & 52 \\
\hline $4 \mathrm{kypc}$ & & & & & & 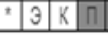 & \begin{tabular}{|l|l|l|}
$\Pi$ & $\Pi$ \\
\end{tabular} & & & & \begin{tabular}{|l|l|l|}
3 & 5 \\
\end{tabular} & $\begin{array}{llll} & \Gamma & \Gamma \\
\end{array}$ & $\begin{array}{lll}r & \mathrm{~K} \\
\end{array}$ & \begin{tabular}{|l|l|l|}
$K$ & $K$ \\
\end{tabular} & & \begin{tabular}{l|l|l}
$\mathrm{K}$ & $\mathrm{K}$ & $\mathrm{K}$ \\
\end{tabular} & 32 & $2-$ & $4-$ & & 4 & & 52 \\
\hline & & & & & & & & & & & & & & & & UTore & \begin{tabular}{l|l|l} 
roo & 141 \\
\end{tabular} & 101 & & 10 & 43. & & \begin{tabular}{|l|l|}
4 & 208 \\
\end{tabular} \\
\hline
\end{tabular}

Рис. 1. Учебный план подготовки бакалавра по профилю «музыкальное образование»

мире также изучаются на данном курсе для системного решения задач в художественно-педагогической деятельности и анализа основных тенденций ее развития [7].

Таким образом, учебная программа по специальности музыкального образования представляет собой совокупность учебных дисциплин, цели программы, планируемых результатов, учебного плана для эффективной организации образовательного процесса. Что касается учебной программы по специальности музыкального образования, то на примере программы РПГУ им. Герцена было выявлено, что в каждой программе необходимы предметы, которые отражают направление подготовки и являются основополагающими в процессе обучения будущего педагога. Немаловажно и материально-техническое оснащение, которое также необходимо для выполнения учебного плана, которые закреплен в учебной программе. Учебный план также является одной из главных составляющих учебной программы, который представляет собой часть учебной программы, являющейся характеристикой образования и определяет количество учебных дней, недель, продолжительность каникул, производственной практики, экзаменационной сессии, научно-исследовательской работы, подготовки к летней школе.

\section{ЛИТЕРАТУРА}

1. Адамчик М.В. Всемирный энциклопедический словарь // М.: Современный литератор. - 2007. - 1648 C.

2. Татур Ю. Образовательные программы: традиции и новаторство // Высшее образование в России. - 2000. №4. - С. 12 - 16

3. «История художественной культуры» // Сайт РПГУ им. А.И. Герцена URL: https://atlas.herzen.spb.ru/disc_annotation.php?disc_id=1247 (Дата посещения 19.12.2019)

4. «Музыкальная информатика» // Сайт РПГУ им. А.И. Герцена URL: https://atlas.herzen.spb.ru/disc_annotation.php?disc_id=4819 (Дата посещения 19.12.2019)

5. «Педагогика» // Сайт РПГУ им. А.И. Герцена URL: https://atlas.herzen.spb.ru/disc_annotation.php?disc_id=1122 (Дата посещения 20.12.2019)

6. «Музыкальная психология» // Сайт РПГУ им. А.И. Герцена URL: https://atlas.herzen.spb.ru/disc_annotation.php?disc_id=46 (Дата посещения 20.12.2019)

7. «История и теория музыкального образования» // Сайт РПГУ им. А.И. Герцена URL: https://atlas.herzen.spb.ru/disc_annotation.php?disc_id=7300 (Дата посещения 20.12.2019)

8. С. 2 Федерального закона от 29.12.2012 N 273-Ф3 (ред. от 02.12.2019) «0б образовании в Российской Федерации» // СПС «КонсультантПлюс» 